Abanico Veterinario. Enero-Diciembre 2020; 10:1-15 http://dx.doi.org/10.21929/abavet2020.21

Artículo Original. Recibido: 13/02/2020. Aceptado: 18/08/2020. Publicado: 26/10/2020. Clave:2020-12.

\title{
Variación genética de Staphylococcus aureus causante de mastitis en vacas lecheras en Jalisco
}

Genetic variation of Staphylococcus aureus causing mastitis in dairy cows in Jalisco

\section{Castañeda-Vázquez Hugo*1 ID, Padilla-Ramírez Francisco**2 ID, Castañeda-Vázquez Martha $^{1 \text { ID }}$, Camacho-Palafox José ${ }^{\text {ID }}$, Salas-Castañeda Erika ${ }^{1 \text { ID }}$}

${ }^{1}$ Universidad de Guadalajara, Laboratorio de Mastitis y diagnóstico Molecular. División de Ciencias Veterinarias, Guadalajara, México. ${ }^{2}$ Universidad de Guadalajara, Departamento de Producción Animal. División de Ciencias Veterinarias, Guadalajara, México. *Autor responsable: Castañeda-Vázquez Hugo. ${ }^{* *}$ Autor de correspondencia: Padilla-Ramírez Francisco². Centro Universitario de Ciencias Biológicas y Agropecuarias, Camino Ramón Padilla Sánchez \#2100 Nextipac, 45200, Zapopan, Jalisco, 37771150 Ext. 33177. hcastane59@yahoo.com.mx, fjavier.padilla@academicos.udg.mx, arcoiris2565@hotmail.com, ertytres333@hotmail.com, erika.salas@cucba.udg.mx.

\section{Resumen}

Se determinó la variabilidad genética de las cepas de $S$. aureus aisladas de algunos casos de mastitis bovina. Se muestrearon 335 vacas de 27 establos en 10 municipios del estado de Jalisco. Las cepas de $S$. aureus se identificaron a partir de muestras de leche de cada glándula mamaria de cada vaca, las cuales se cultivaron en agar sangre y con base a las características del cultivo, las pruebas bioquímicas, y finalmente su confirmación molecular mediante PCR. La variación genética en las cepas identificadas se obtuvo con la técnica de electroforesis de campos pulsados. Las imágenes de los geles se analizaron mediante el software Bionumerics ${ }^{\circledR}$. Se diagnosticó con la prueba de California un $2.26 \%$ de mastitis clínica y un $40.45 \%$ de mastitis subclínica. Se registró una frecuencia de aparición de $S$. aureus del $9.8 \%$ del total de las glándulas muestreadas. Se observó una variación genética de $14.9 \%$. Las 32 cepas analizadas se agruparon en pulsotipos con 95\% o más de similitud genética, resultando 12 pulsotipos. Se concluye que existe gran diversidad en la variabilidad genética de cepas de $S$. aureus de diferentes establos del estado de Jalisco y una gran similitud genética de cepas dentro de cada establo.

Palabras clave: Staphylococcus aureus, tipificación, frecuencia de mastitis, variación genética, electroforesis de campos pulsados.

\begin{abstract}
The genetic variability of $S$. aureus strains isolated from some cases of bovine mastitis was determined. 335 cows from 27 stables were sampled in 10 municipalities in the state of Jalisco. S. aureus strains were identified from milk samples of each mammary gland of each cow, which were grown in blood agar and based on the characteristics of the culture, biochemical tests, and finally their molecular confirmation by PCR. The genetic variation in the strains was identified by pulsed- field electrophoresis technique. The images of the gels were analyzed using the Bionumerics ${ }^{\circledR}$ software. $2.26 \%$ of clinical mastitis and $40.45 \%$ of subclinical mastitis were diagnosed with the California test. A frequency of appearance of $S$. aureus of $9.8 \%$ of the total sampled glands was recorded. A genetic variation of $14.9 \%$ was observed. The 32 strains analyzed were grouped into pulsotypes with $95 \%$ or more of genetic similarity, resulting in 12 pulsotypes. It is concluded that there is great diversity in the genetic variability of $S$. aureus strains from different stables in the state of Jalisco and a great genetic similarity of strains within each stable.

Keywords: PFGE, S. aureus, typification, frequency of mastitis, genetic variation, pulsed field electrophoresis.
\end{abstract}




\section{INTRODUCCIÓN}

La mastitis es definida como la inflamación de la glándula mamaria, causada principalmente por patógenos (Bedolla et al., 2008), que ocasiona una disminución en la producción y calidad de la leche en su forma subclínica; sin embargo puede convertirse en mastitis clínica, donde puede llegar hasta el desecho del animal por pérdida de la funcionalidad de la glándula mamaria (Echeverri et al., 2010). Asimismo la mastitis subclínica suele estar presente por mayor tiempo y es más frecuente que la mastitis clínica (Bedolla et al., 2007). Las pérdidas económicas pueden alcanzar hasta cinco mil pesos por cada lactancia de una vaca al año (Van et al., 2016); aunque se han encontrado alrededor de 137 microorganismos en ganado lechero con mastitis, sólo un reducido número de patógenos son los responsables de la mayoría de los casos (Wolter et al., 2004); por ejemplo, tal es el caso del género Staphylococcus spp, que expresan factores de virulencia que permiten su persistencia y distribución en el huésped (Marqués et al., 2013).

Por otra parte Staphylococcus aureus, descrito por el médico Alexander Ogston en 1880 (Cervantes-García et al., 2014), el cual en la actualidad es considerado como uno de los principales agentes causantes de mastitis a nivel mundial (El-Sayed, 2006b), con una frecuencia de casi el 30\% de muestras de vacas con mastitis (Calderón y Rodríguez, 2008). A este patógeno se le atribuyen propiedades invasivas y factores extracelulares como la producción de toxinas que conducen al síndrome de shock tóxico, toxinas exfoliativas y enterotoxinas estafilocócicas (Vasconcelos and Ribeiro de Souza, 2010). Adicionalmente, posee una gran capacidad de adquirir elementos exógenos por transferencia horizontal, lo que le permite adaptarse fácilmente al medio y a los agentes antimicrobianos, mediante la adquisición de factores de resistencia a antibióticos codificados por plásmidos y transposones (Baba et al., 2002).

La tipificación molecular de microorganismos (genotipificación) es muy importante para conocer la evolución de los patógenos y estudiar su relación genética; de esta manera se logra un mayor entendimiento durante las investigaciones epidemiológicas (Amr ElSayed, et al., 2017; Castañeda et al., 2018, García et al., 2019). Existe una variedad de métodos de genotipificación, cada técnica presenta fortalezas y debilidades. Entre los más destacados se encuentran la electroforesis de campos pulsados (PFGE), tipificación del gen spa, tipificación de secuencias de locus múltiple (MLST), el análisis de perfil de plásmido, polimorfismo de longitud de fragmento de restricción (RFLP), análisis (MLVA), y el análisis de toda la secuencia del genoma ADN (Struelens et al, 2009; Kuroda et al., 2001).

La electroforesis de campos pulsados (PFGE), es una poderosa técnica de genotipificación utilizada para separar grandes moléculas de ADN (ADN genómico completo), después de una macrorestricción (corte con una enzima de restricción en 
varios puntos del genoma) y la separación de fragmentos mediante la aplicación de un campo eléctrico; siendo esta técnica una buena representación de todo el cromosoma bacteriano, porque proporciona fragmentos de ADN claramente diferenciados (SharmaKuinkel et al., 2016). Una de las fortalezas de la técnica es que presenta un alto poder discriminatorio (Struelens et al, 2009). Castañeda et al., (2011) mostró una estrecha relación de cepas de campo de $S$. aureus, responsables de mastitis en el occidente de México; sugiriendo que clones estrechamente relacionados de $S$. aureus son los responsables de la mayoría de las infecciones intramamarias, provocadas en el estado de Jalisco (Castañeda et al., 2018). Marqués et al., (2013) observaron en Brasil una marcada diversidad de clones de $S$. aureus, detectando seis perfiles genéticos distintos mediante la electroforesis de campos pulsados (PFGE). (Kuroda et al., 2001; Sato et al.,2017) encontraron variaciones genéticas de hasta $30 \%$ de 41 cepas de $S$. aureus, aisladas en Japón de vacas con mastitis, humanos y en carne destinada a la venta. (Can et al., 2017), obtuvieron una variación de alrededor del $25 \%$ de la totalidad de muestras obtenidas de muestras de carne, leche cruda, queso, carne y pollo en Turquía. Las cepas obtenidas de leche de vaca cruda presentaron una similitud del $90 \%$.

Sólo una investigación exhaustiva nos ayudará a comprender la epidemiología del patógeno $S$. aureus, y puede ayudar a controlar la enfermedad y/o producir una vacuna, minimizando su amenaza. Para este propósito, varias herramientas de biología molecular han sido desarrolladas para su uso en estudios epidemiológicos moleculares avanzados, como las utilizadas en la presente investigación de $S$. aureus.

\section{MATERIAL Y MÉTODOS}

Muestreo. Se realizó un estudio transversal con un muestreo aleatorio en 27 establos pertenecientes a los 10 municipios: Acatic, Arandas, Atotonilco el Alto, Encarnación de Díaz, la Barca, Lagos de Moreno, Tepatitlán de Morelos, San Juan de los Lagos, San Miguel el Alto y Tototlán, considerados los mayores productores de leche del estado de Jalisco, México.

El número de animales muestreados fue proporcional a la población de vacas de cada municipio, en una relación de 1 a 900 aproximadamente. El tamaño de los establos se clasificó por el número de vacas en producción, que al momento del muestreo presentaba cada establo, y con base a esto se determinó el número de vacas a muestrear en cada uno (tabla 1). El número total de vacas a muestrear se determinó con la fórmula empleada para poblaciones infinitas o muy grandes (Gamboa, 2017), dando como resultado 335 vacas.

Detección de mastitis. Se utilizó la prueba de California como prueba de campo para la determinación de la frecuencia de mastitis subclínica; se realizó antes del ordeño del animal, después de eliminarse los primeros chorros de leche; tomándose una muestra aproximada de $2 \mathrm{~mL}$ y aplicando una cantidad similar del reactivo de California Mastitis 
Test (CMT), por sus siglas en inglés; siguiendo el procedimiento propuesto por (Barnum y Newbould, 1961), después de unos movimientos circulares de la mezcla se procedió inmediatamente a su interpretación.

Tabla 1. Clasificación de establos por su tamaño (número de vacas en producción)

\begin{tabular}{ccc}
\hline Tamaño del establo & No. De Vacas en producción & No. de Vacas a muestrear \\
\hline Chico & $\leq 25$ & $\leq 11$ \\
Mediano & 26 a 99 & 12 a 15 \\
Grande & $\geq 100$ & 16 a 20 \\
\hline
\end{tabular}

El cultivo bacteriológico, las pruebas bioquímicas, la técnica de PCR; así como la electroforesis de campos pulsados se realizaron en el laboratorio de mastitis y biología molecular del Centro Universitario de Ciencias Biológicas y Agropecuarias (CUCBA) de la Universidad de Guadalajara, el cual se encuentra ubicado en el municipio de Zapopan del estado de Jalisco. Las 1,325 muestras de leche se cultivaron en cajas de Petri, con contenido de agar sangre adicionado con sangre de borrego al 5\%, inoculando alrededor de $0.01 \mathrm{~mL}$ de leche por cada muestra.

Identificación presuntiva de $\boldsymbol{S}$. aureus. Se empezó con la identificación mediante la observación de las características propias de la colonia (presencia y tipo de hemolisis, color y textura). Después se procedió a realizar las siguientes 3 pruebas bioquímicas: Prueba de coagulasa en tubo (Sperber y Tatini., 1975), prueba de sal manitol (CervantesGarcía et al., 2014) y prueba de DNasa (Menzies, 1977).

Identificación molecular de $\boldsymbol{S}$. aureus. Se utilizó la técnica de reacción en cadena de la polimerasa (PCR), ya que permite la identificación de patógenos proporcionando una alta sensibilidad y especificidad, siendo la prueba estándar de oro para la identificación de especies (El-Sayed et al., 2017).

Extracción del ADN. Se realizó el método de extracción con lisoestafina propuesto por Chapaval et al., (2008), con algunas modificaciones. De los cultivos de $S$. aureus sembrados en agar sangre de 18 - 24 horas en incubación, se tomaron 2 asadas y se depositaron en $200 \mu \mathrm{L}$ de una solución de TE (10 mM Tris - 1 mM EDTA), pH 8. Posteriormente se añadió $2 \mu \mathrm{L}$ de lisoestafina $(1 \mathrm{mg} / \mathrm{mL})$ y se incubó por 2 horas a $37^{\circ} \mathrm{C}$, se le añadieron $200 \mu \mathrm{L}$ de la mezcla fenol-cloroformo-alcohol isoamílico (25-24-1), se agitó a velocidad alta (3,000 rpm) en vortex por 3 segundos y se metió a centrifugar a 12,000 rpm por 10 minutos; se pasó $150 \mu \mathrm{L}$ del sobrenadante a otro tubo y se le añadió $60 \mu \mathrm{L}$ de $\mathrm{NaCl} 5 \mathrm{M}$ y $300 \mu \mathrm{L}$ de etanol al $96 \%$ y se metió a $-20^{\circ} \mathrm{C}$ por $2 \mathrm{~h}$ para precipitar el ADN. Posteriormente se centrifugó a 12,000 rpm. por 15 min y se descartó el 
sobrenadante, teniendo cuidado de no descartar el pellet formado. Después se añadió $200 \mu \mathrm{L}$ de etanol al $70 \%$ y se centrifugó a 12,000 rpm por 10 minutos, descartando el etanol. Se mantuvieron los tubos abiertos frente al mechero por 30 min para que evaporaran los restos de etanol. Por último, se colocaron $50 \mu \mathrm{L}$ de TE, $\mathrm{pH} 8$.

Primers y Programa de PCR .

Se utilizaron los siguientes primers para la amplificación del gen 23 rDNA

Secuencia 5' (ACG GAG TTA CAA AGG ACG AC)

Secuencia 3' (AGC TCA GCC TTA ACG AGT AC)

Y para la amplificación del gen se utilizó el siguiente programa:

Etapa 1 (1 ciclo): paso 1. Desnaturalización $\left(94^{\circ} \mathrm{C}\right.$ por 5 min)

Etapa 2 (37 ciclos): paso 1. Desnaturalización $\left(94^{\circ} \mathrm{C}\right.$ por $\left.40 \mathrm{~s}\right)$

Paso 2. Alineamiento $\left(58^{\circ} \mathrm{C}\right.$ por $\left.60 \mathrm{~s}\right)$

Paso 3. Extensión $\left(72{ }^{\circ} \mathrm{C}\right.$ por $\left.75 \mathrm{~s}\right)$

Etapa 3 ( 1 ciclo): paso 1 . Extensión $\left(72{ }^{\circ} \mathrm{C}\right.$ por $5 \mathrm{~min}$ ) (El-Sayed et al., 2006b).

Electroforesis. Para la electroforesis se usó un gel de agarosa al 1\%, el cual se corrió a 70 v por 40 min, utilizando el buffer TBE 1x (89 mM Tris - 89 mM Borato - 2 mM E.D.T.A), $\mathrm{pH} 8$.

Determinación de la variación genética. Se utilizó la técnica de electroforesis de campos pulsados (PFGE), por sus siglas en inglés, misma técnica utilizada por Sato et al., (2017), para la determinación de la variabilidad genética de $S$. aureus. Solo las cepas diagnosticadas positivas a $S$. aureus, mediante PCR fueron consideradas para la determinación de la variación genética. En total se seleccionaron 32 cepas de $S$. aureus.

Se elaboró la técnica utilizada por Castañeda et al., (2011), con algunas modificaciones. Se inocularon las cepas en placas de agar sangre y se incubaron a $37^{\circ} \mathrm{C}$ durante 18 horas. De cada cepa bacteriana se tomó una azada del cultivo y se suspendió en $200 \mu \mathrm{L}$ de la solución PIV $(0,01 \mathrm{mM}$ Tris, $1 \mathrm{M} \mathrm{NaCl}) \mathrm{pH} 8$, y se ajustó a una densidad óptica de 1.5 con un nivel de absorbancia de $610 \mathrm{~nm}$. De esta solución se tomaron $60 \mu \mathrm{L}$ de cada muestra y se mezclaron con $60 \mu \mathrm{L}$ de agarosa al $1 \%$ (disuelta en TE), conservada a una temperatura de $45^{\circ} \mathrm{C}$. Posteriormente se pasaron a un compartimento del molde para bloques y se esperaron unos 15 minutos a que solidificaran. Los bloques se pasaron a un tubo de $1.5 \mathrm{~mL}$ que contenía: $0.5 \mathrm{~mL}$ de la solución de lisis $(6 \mathrm{mM}$ Tris - $1 \mathrm{M} \mathrm{NaCl}$ $100 \mathrm{mM}$ E.D.T.A - 0.2\% desoxicolato sódico - 0.5\% sarcosyl), $25 \mu \mathrm{L}$ de brij 58 (al 10\%), $5 \mu \mathrm{L}$ de lisozima $(50 \mathrm{mg} / \mathrm{mL})$, y $5 \mu \mathrm{L}$ de lisoestafina $(1 \mathrm{mg} / \mathrm{mL})$; se mezcló y se incubaron 
a $37^{\circ} \mathrm{C}$ durante 21 horas. Se decantó la solución y se sustituyó por $0.5 \mathrm{~mL}$ de la solución ES (500 mM E.D.T.A - $1 \%$ sarcosyl) y se agregaron $25 \mu \mathrm{L}$ de proteinasa $\mathrm{K}(20 \mathrm{mg} / \mathrm{mL})$. Se incubaron a $56{ }^{\circ} \mathrm{C}$ durante $21 \mathrm{~h}$. Se decantó la solución ES y los bloques se lavaron 5 veces, agitándose de manera suave por 20 min con $10 \mathrm{~mL}$ de TE $(10 \mathrm{mM}$ Tris - $1 \mathrm{mM}$ EDTA) por cada lavado. Se cortó una rebanada de $3 \mathrm{~mm}$ de cada bloque.

Para la digestión se agregaron $100 \mu \mathrm{L}$ de la solución para restricción: agua $87.75 \mu \mathrm{L}$, buffer (10x) $10 \mu \mathrm{L}$, enzima Sma1 1.25 $\mu \mathrm{L}$ (12.5 U por muestra) y albúmina de suero de bovino (BSA) $1 \mu \mathrm{L}$. Se dejó incubar 3 horas a $25^{\circ} \mathrm{C}$. Posteriormente las rebanadas se colocaron en el interior de un gel de agarosa al $1 \%$ en TBE $0.5 \times \mathrm{pH}$ 8. Se realizó la electroforesis en $7 \mathrm{~L}$ 0.5x TBE pH 8 en el aparato Chef-DR II (Bio-Rad).

El programa utilizado fue: Voltaje $6 \mathrm{~V} / \mathrm{cm}$, temperatura $14{ }^{\circ} \mathrm{C}$; tiempo inicial $5 \mathrm{~s}$; tiempo final $40 \mathrm{~s}$; y duración $21 \mathrm{~h}$. Posteriormente, el gel se tiñó y se capturó la imagen en un fotodocumentador.

La determinación de la variación genética se realizó analizando las imágenes de los geles, obtenidos mediante la técnica PFGE, a partir de dendrogramas para la determinación del parentesco, con la ayuda del software Bionumerics ${ }^{\circledR}$ (Applied Maths, Kortrijk, Belgium). Se utilizó el coeficiente de correlación de Dice y el algoritmo de agrupación de promedio matemático del grupo de pares no ponderado (UPGMA). Se elaboró un dendrograma de similitud del total de las muestras y otros 3 dendrogramas (uno por cada región muestreada). Los porcentajes de similitud genética se pudieron obtener con la elaboración de los dendrogramas.

\section{RESULTADOS}

Frecuencia de mastitis. De las 1,340 glándulas mamarias correspondientes a las 335 vacas muestreadas, se obtuvieron los siguientes resultados. Analizando 1,325 glándulas mamarias funcionales y 15 glándulas ciegas (no funcionales), se observó una frecuencia del $42.71 \%$ de mastitis, de la cual la mastitis clínica representó el $2.26 \%$ y de la mastitis subclínica el $40.45 \%$.

Frecuencia de agentes etiológicos. De las 1,325 muestras recolectadas de leche se obtuvo un crecimiento positivo de S. aureus en 130 muestras (correspondientes al 9\% del total) y un crecimiento de 261 de estafilococos coagulasa negativo ( $18 \%$ del total). Por lo que refleja la importancia del género Staphylococcus spp, ya que representó un crecimiento del $27 \%$ del total de las muestras.

Variación genética de $S$. aureus mediante la técnica de electroforesis de campos pulsados (PFGE). Se obtuvieron los siguientes perfiles genéticos (pulsotipos) de 32 cepas de $S$. aureus representativas aisladas de establos mediante la técnica de PFGE (figura 1). 


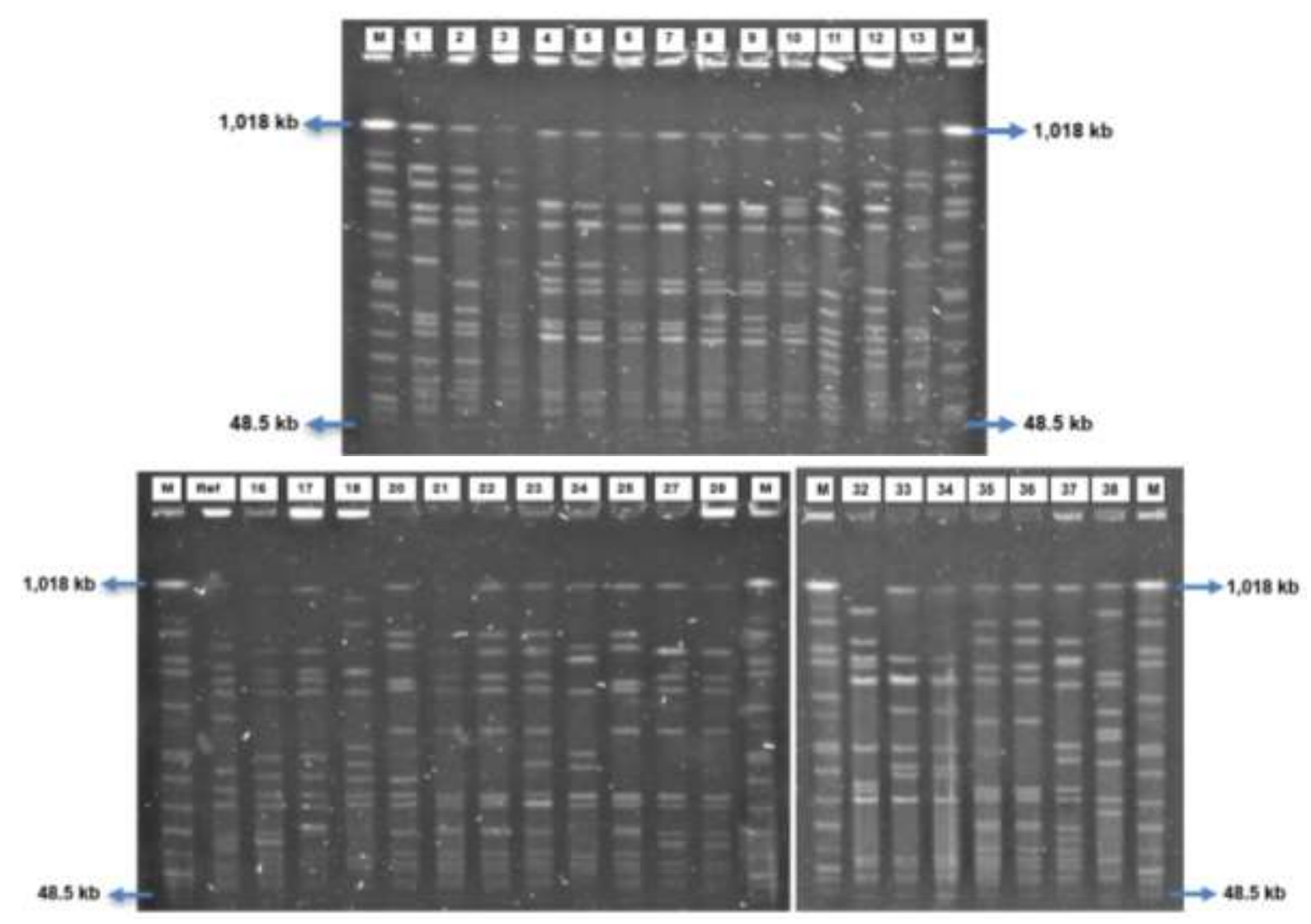

Figura 1. Electroforesis de campos pulsados del ADN (después de la digestión con la enzima de restricción sma1) de las 32 cepas de $S$. aureus aisladas de vacas lecheras del estado de Jalisco. Donde $M=$ Marcador de peso molecular de 48.5kb a 1,018kb (New England Biolabs), Ref= Cepa de referencia S. aureus (ATCC 25923) y número del 1 al 38= al total de cepas aisladas (32).

Se elaboraron dendrogramas para la determinación de la variación genética de $S$. aureus. Los 32 pulsotipos de las cepas estudiadas se agruparon en 12 diferentes agrupaciones de pulsotipos, con un $95 \%$ o más de similitud genética dentro de cada grupo de pulsotipos.

Se obtuvo un porcentaje de similitud genética del $85.1 \%$, lo que corresponde al $14.9 \%$ de variación genética de los 32 pulsotipos de cepas aisladas, de los 10 municipios muestreados del estado de Jalisco. La agrupación de pulso tipos (p3), fue el mayormente encontrado agrupando al 25\% (8/32) del total de los pulsotipos de las cepas analizadas (figura 2). 


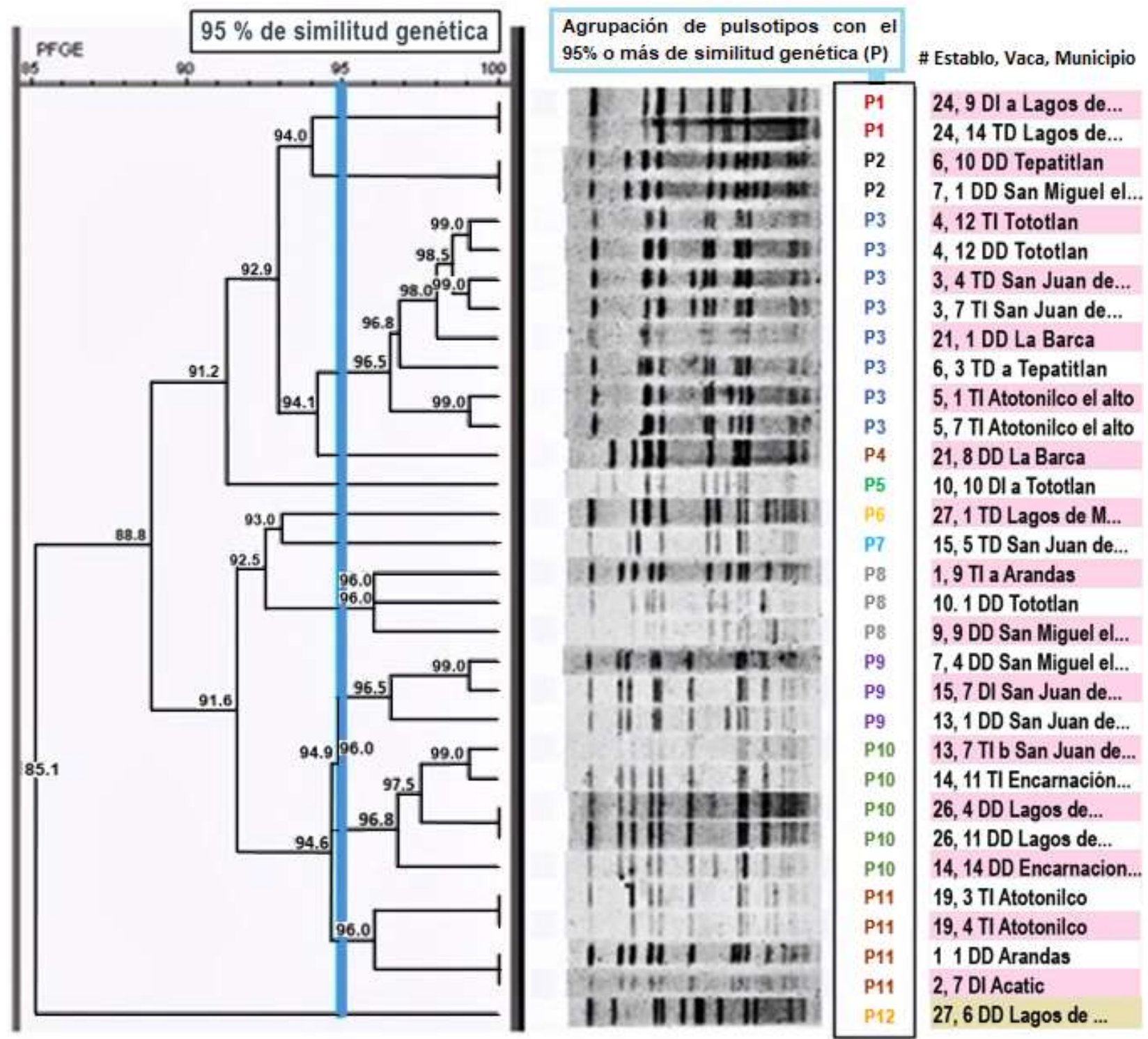

Figura 2. Dendrograma de los pulsotipos de las 32 cepas de $S$. aureus aisladas en diferentes regiones del estado de Jalisco

En el dendrograma de los pulsotipos de las cepas aisladas de la región Altos Norte, se observó un $84.9 \%$ de similitud genética, lo que corresponde a el $15.1 \%$ de variación genética de las 14 cepas aisladas de los municipios de Encarnación de Díaz, Lagos de Moreno y San Juan de los Lagos (figura 3). 

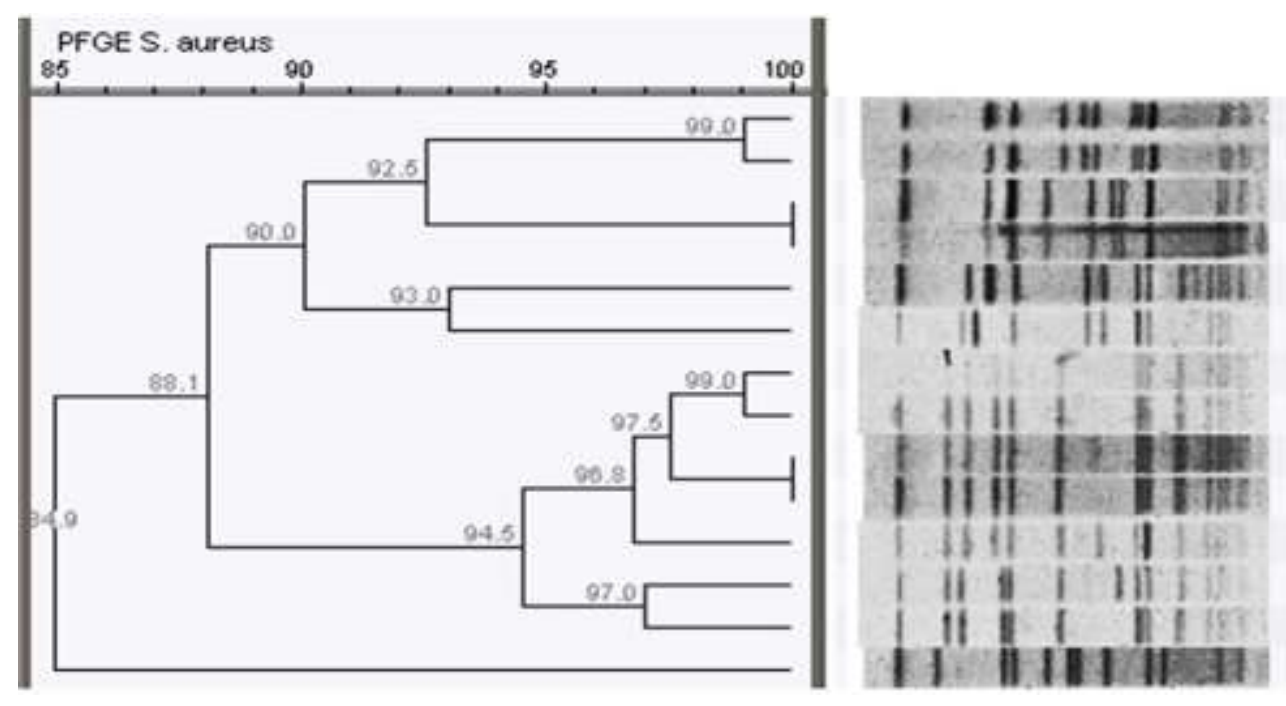
3,4 TD San Juan de 3,7 TISan Juan de I... $24,9 \mathrm{Dl}$ a Lagos de 24,14 TD Lagos de.. 271 TD Lagos de $M$. 15,5 TD San Juan de. $13,7 \mathrm{TI}$ b San Juan d. 14, 11 TI Encarnació.. 26,4 DD Lagos de 26, 11 DD Lagos de. 14,14 DD Encarnaci.. 13,1 DD San Juan d... $15,7 \mathrm{DISan}$ Juan de. 27, 6 DD Lagos de

Figura 3. Dendrograma de los pulsotipos de 14 cepas de $S$. aureus aisladas en la región Altos Norte del estado de Jalisco

En el dendrograma de los pulsotipos de las cepas aisladas de la región Altos Sur, se observó un $89.8 \%$ de similitud genética, lo que corresponde a el $10.2 \%$ de variación genética de las 8 cepas aisladas de los municipios de Acatic, Arandas, San Miguel el alto y Tepatitlán de Morelos (figura 4).

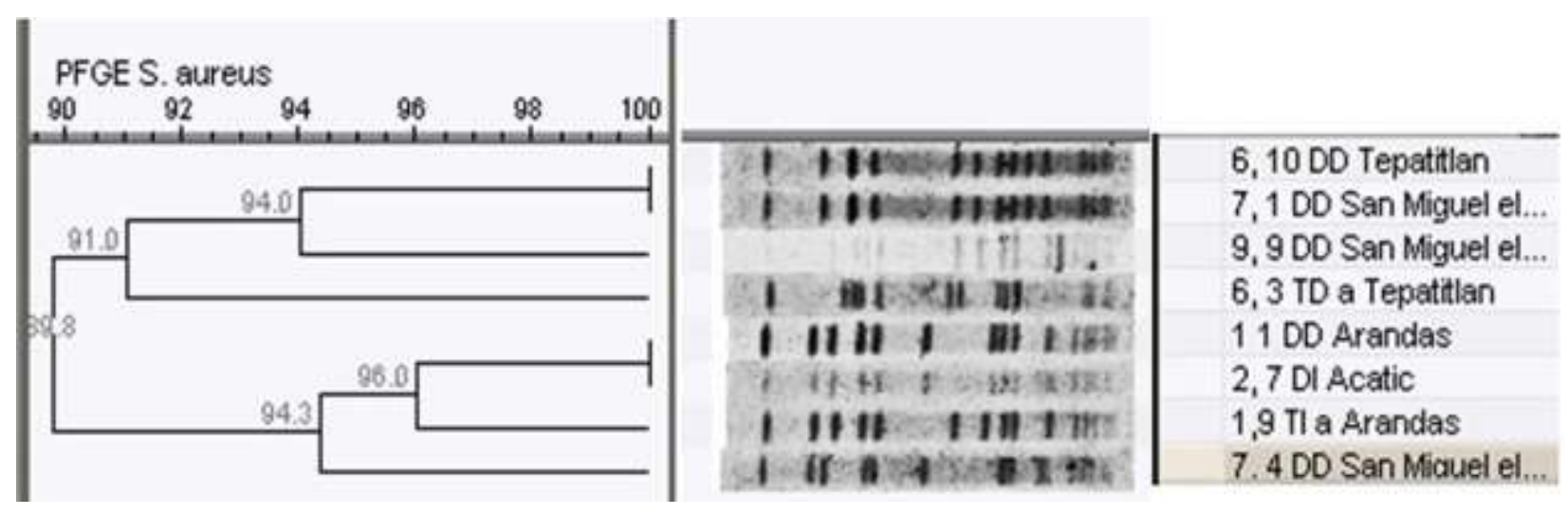

Figura 4. Dendrograma de los pulsotipos de 8 cepas de $S$. aureus aisladas en la región Altos Sur del estado de Jalisco

En el dendrograma de los pulsotipos de las cepas aisladas de la región Ciénega, se observó un porcentaje del $90.2 \%$ de similitud genética, lo que corresponde a el $9.8 \%$ de variación genética de las 10 cepas aisladas de los municipios de Atotonilco el Alto, la Barca y Tototlán (figura 5). 


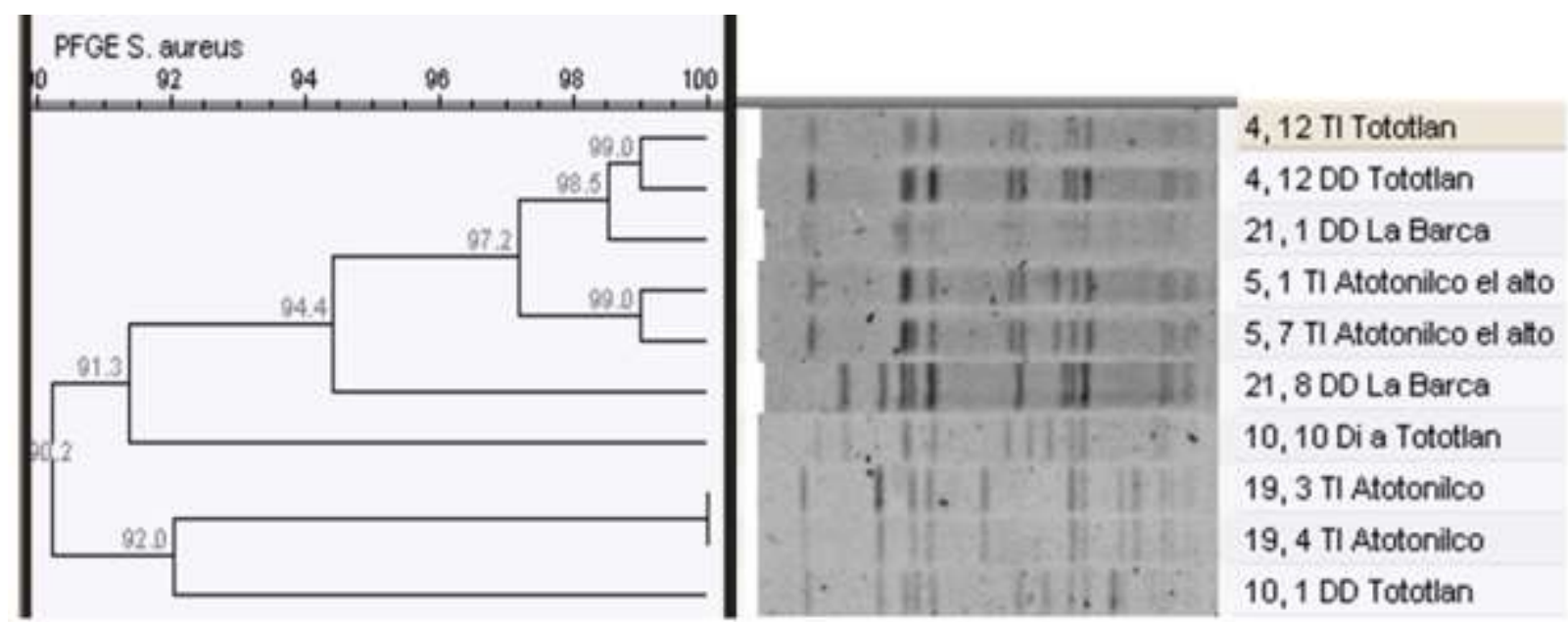

Figura 5. Dendrograma de los pulsotipos de 10 cepas de $S$. aureus aisladas en la región Ciénega del estado de Jalisco

Dentro de la relación de las características morfológicas de las cepas estudiadas con su perfil genético (pulsotipo) en la técnica de la variación genética, se pudo observar que las cepas de S. aureus que resultaron idénticas en la técnica de PFGE (similitud del 100\%) presentaron características morfológicas idénticas. Mientras que la cepa (38. 27, 6 DD) resaltó de todas las demás en su cultivo, ya que mostró una pronunciada hemolisis beta de $15 \mathrm{~mm}$; de igual forma fue la cepa que presentó el pulsotipo con la mayor variación genética en la técnica de PFGE.

\section{DISCUSIÓN}

A partir de los hallazgos encontrados se establece que se encuentran variaciones genéticas mayores a un 10\% de Staphylococcus aureus aislados de vacas lecheras del estado de Jalisco, encontrándose el $14.9 \%$ de variación genética entre las 32 cepas analizadas en este estudio. Los resultados relacionados con la variación genética observados en el presente trabajo son similares a los citados por Can et al., (2017), quienes encontraron una relación genética del $90 \%$ de cepas aisladas de leche cruda de vaca en Turquía, lo que corresponde al 10\% de variación genética. En ese mismo estudio se analizaron en conjunto las cepas de $S$. aureus obtenidas de muestras de leche cruda de vaca, muestras de carne, queso y pollo en Turquía; en donde la variación genética aumentó hasta un $25 \%$, lo que supone que existen tipos de perfiles genéticos similares genéticamente en las muestras de leche; quizás debido a que los $S$. aureus aislados de leche presentan un genotipo relativamente similar, ya que requieren de las mismas características que les permita estar adaptados, tanto dentro como fuera de la glándula mamaria.

Los resultados mostrados en este estudio son similares a los resultados realizados por Castañeda et al., (2011), quienes concluyeron que existe una estrecha relación genética 
de S. aureus, responsables de mastitis; sugiriendo que clones estrechamente relacionados de $S$. aureus, son los responsables de la mayoría de las infecciones intramamarias provocadas en el estado de Jalisco. Sin embargo difieren de los resultados generados con los obtenidos por Sato et al., (2017), quienes encontraron variaciones genéticas de hasta el $30 \%$ de 41 cepas de $S$. aureus aisladas en Japón; tal vez debido a que se tomarán además cepas aisladas de humanos y de carne destinada a la venta; por lo que parece comprensible el alto porcentaje de variación mostrado, ya que las cepas suelen desarrollar características elementales que le permiten adaptarse a las condiciones del sitio de donde son aisladas.

Aunque en la frecuencia de mastitis se obtuvo un porcentaje alto (42.71\%) en las vacas muestreadas, sólo alrededor del $20 \%$ de las glándulas mamarias muestreadas representó a la mastitis clínica y a los grados 2 y 3 de la mastitis subclínica; por lo que alrededor del $80 \%$ de las glándulas se identificaron como negativo a mastitis y a mastitis subclínica grado 1. Por otra parte en un estudio realizado por Manjarrez et al., 2012, encontró una frecuencia mayor de mastitis en el estado de México; quienes citan un $6.1 \%$ de mastitis clínica y un $48.3 \%$ de mastitis subclínica, siendo esto comprensible ya que se muestrearon sólo establos pequeños de tipo familiar, que presentaban poco nivel de tecnificación; lo que representa deficiencias en la técnica de ordeño y poco control de la mastitis, defiriendo del muestreo de nuestro estudio en el cual se eligieron además de establos familiares, establos semitecnificados y tecnificados; por lo que resultó menor la frecuencia de mastitis obtenida en nuestro estudio.

Por otro lado Yera y Ramírez, 2016, registraron una frecuencia de aparición de $S$. aureus del $8.75 \%$ en vacas mestizas Holstein x Cebú, frecuencia menor a la obtenida que fue del 9.8\%; quizás por una mejor resistencia a la infección de los animales muestreados al ser animales híbridos. Boscán et al., (2009), observó una frecuencia de aparición de $S$. aureus del $12.15 \%$, mayor a la presentada en este estudio, difiriendo además de la metodología de muestreo, ya que se tomaron muestras de leche sólo en vacas diagnosticadas con mastitis subclínica y que se encontraban en el inicio del periodo seco. Castañeda et al., (2013), en el estado de Jalisco, mostró una frecuencia de $S$. aureus a nivel de establo del $100 \%$, siendo la frecuencia más elevada a la mostrada, que fue del $66.7 \%$; probablemente debido a que en ese estudio sólo se sembró leche perteneciente de glándulas diagnosticadas con mastitis; caso contrario a nuestro estudio, el cual se sembraron todas las muestras de leche sin importar su resultado en el diagnóstico de mastitis.

\section{CONCLUSIONES}

La agrupación de pulsotipos P3 de $S$. aureus representó el 25\% del total de los perfiles genéticos (pulsotipos) de las cepas aisladas (8/32), estando presente en todas las regiones que se muestrearon de Jalisco. La variación genética comparada con la 
variación morfológica resultó idéntica. Asimismo, las cepas aisladas dentro de un mismo establo presentaron una notable similitud genética, llegando al $100 \%$ de similitud en varios establos. Los resultados del presente estudio aportan información valiosa que puede ser complementaria en el área de la epidemiología molecular necesaria para el control, tratamiento y para la producción de vacunas necesarias para la mastitis causada por S. aureus.

\section{LITERATURA CITADA}

BABA T, Takeuchi F, Kuroda M, Yuzawa H, Aoki KC, Oguchi A, Nagai Y, Iwama N, Asano K, Naimi T, Kuroda H, Cui L, Yamamoto K, Hiramatsu K. 2002. Genome and virulence determinants of high virulence community acquired MRSA. Lancet. 359: 1819-1827. https://doi.org/10.1016/S0140-6736(02)08713-5

BARNUM DA, Newbould FHS. 1961. The use of the California mastitis test for the detection of bovine mastitis. The Canadian Veterinary Journal, 2(3), 83. https://www.ncbi.nlm.nih.gov/pmc/articles/PMC1585631/

BEDOLLA CC, Ponce de León MER. 2008. Pérdidas económicas ocasionadas por la mastitis bovina en la industria lechera. Rev Electrón Vet. 9: 1-26. http://www.redalyc.org/articulo.oa?id=63611952010

BEDOLLA CC, Castañeda VH, Wolter W. 2007. Métodos de detección de mastitis bovina. Rev Electrón Vet. 8: 1-17. http://agris.fao.org/agrissearch/search.do?recordID=DJ2012036579

BOSCÁN J, Villaroel R, Oviedo A, Sánchez A, Pino D, García D, Hernández L, Pérez M. 2009. Bacterias patógenas potenciales al inicio del período seco de vacas doble propósito con mastitis subclínicas. Revista Científica de Maracaibo. 19: 277- 283. http://www.redalyc.org/articulo.oa?id=95911669010

CALDERÓN A, Rodríguez V. 2008. Prevalencia de mastitis bovina y su etiología infecciosa en sistemas especializados en producción de leche en el altiplano cundiboyacense (Colombia). Revista colombiana de ciencias pecuarias. 21: 582-589. https://dialnet.unirioja.es/servlet/articulo?codigo=2897973

CAN HY, Elmalı M, Karagöz A. 2017. Molecular typing and antimicrobial susceptibility of Staphylococcus aureus strains isolated from raw milk, cheese, minced meat, and chicken $\begin{array}{llllll}\text { meat samples. Korean } J \text { Food } & \text { Sci } & \text { 37. }\end{array}$ https://doi.org/10.5851/kosfa.2017.37.2.175

CASTAÑEDA VH, Jäger S, Wolter W, Zschöck M, Castañeda VMA, El-Sayed A. 2011. Genotyping of Staphylococcus aureus isolated from dairy herds in México. Rev Científic. 21: 308-316. http://www.redalyc.org/articulo.oa?id=95918727005 
CASTAÑEDA VH, Jäger S, Wolter W, Zschöck M, Castañeda VMAC, El-Sayed A. 2013. Isolation and identification of main mastitis pathogens in Mexico. Arq Bras Med Vet Zoo. 65:377-382. https://doi.org/10.1590/S0102-09352013000200012

CASTAÑEDA VH, Wolter W, Serratos JM, Castañeda VM, Salas CEP, Alvarez-Moya C. 2018. Avances en las investigaciones de Staphylococcus aureus como agente patógeno causante de mastitis bovina, mediante biología molecular. En: Bienestar animal en la práctica, en producciones lecheras, desde la perspectiva europea. Edited and published by Frank JCM, Van Eerdenburg. Pp. 108-121.

https://www.dropbox.com/s/q9jdztauo43io26/Bienestar\%20animal\%20en\%20la\%20prac tica.pdf?dl=0

CERVANTES-GARCÍA E, García-González R, Salazar-Schettino PM. 2014. Características generales del Staphylococcus aureus. Rev Latinoam Patol Clin Med Lab. 61: 28-40. https://www.medigraphic.com/cgi-bin/new/resumen.cgi?IDARTICULO=48300

CHAPAVAL L, Moon DH, Gomes JE, Duarte FR, Tsai SM. 2008. An alternative method for Staphylococcus aureus DNA isolation. Arquivo Brasileiro de Medicina Veterinária e Zootecnia: 60(2):299-306.

https://www.scielo.br/scielo.php?pid=S010209352008000200004\&script=sci_arttext

ECHEVERRI JJ, Jeramillo MG, Restrepo LF. 2010. Evaluación comparativa de dos metodologias de diagnóstico de mastitis en un hato lechero del departamento de $\begin{array}{lllll}\text { antioquia. } & \text { Rev. } & \text { Lasallista investig. } & \text { 7: } & \text { 49-57. }\end{array}$ http://www.redalyc.org/articulo.oa?id=69514965007

EL-SAYED A, Alber J, Lämmler C, Abdulmawjood A, Zschöck M, Castaneda VH. 2006a. Comparative sequence analysis of spa gene of Staphylococcus aureus isolated from bovine mastitis: characterization of an unusual spa gene variant. $J$ dairy Res. 73: 322327. https://doi.org/10.1017/S002202990600183X

EL-SAYED A, Alber J, Lämmler C, Jäger S, Wolter W, Castañeda-Vazquez H. 2006b. Comparative study on genotypic properties of Staphylococcus aureus isolated from clinical and subclinical mastitis in Mexico. Vet Mex. 37: 165-179. https://www.medigraphic.com/cgibin/new/resumenl.cgi?IDREVISTA=39\&IDARTICULO=8854\&IDPUBLICACION=976

EL-SAYED A, Walid Awad, Nadra-Elwgoud Abdou, Hugo Castañeda Vázquez. 2017. Molecular biological tools applied for identification of mastitis causing pathogens, International Journal of Veterinary Science and Medicine. 5(2):89-97. https://www.tandfonline.com/doi/full/10.1016/j.ijvsm.2017.08.002 
GAMBOA ME. 2017. Estadística aplicada a la investigación científica. En J.C. Arboleda (Ed.). Apropiación, generación y uso solidario del conocimiento (pp. 59-76). Las Tunas, Cuba: Editorial Redipe-Edacun.

ISBN 9781945570148

http://roa.ult.edu.cu/handle/123456789/3667

GARCíA GM, Montoya GN, López VM, Aguilar MSW, Salvador Lagunas BS, Valladares CB, Vázquez ChJC, Castañeda H, Velázquez OV. 2019. Caracterización de los ecotipos de Staphylococcus aureus en hatos lecheros de producción familiar en el Valle de Toluca, México. Pp. 455-492. En: Temas selectos en la Innovación de las Ciencias Agropecuarias, Ciudad de México: Alfaomega Grupo Editor: Ciudad de México: Universidad del Estado de México. 2019. ISBN 9786075384115

KURODA Makoto Toshiko Ohta, Ikuo Uchiyama, Tadashi Baba, Harumi Yuzawa, Ichizo Kobayashi, Longzhu Cui, Akio Oguchi, Ken-ichi Aoki, Yoshimi Nagai, JianQi Lian, Teruyo Ito, Mutsumi Kanamori, Hiroyuki Matsumaru, Atsushi Maruyama, Hiroyuki Murakami, Akira Hosoyama, Yoko Mizutani-Ui, Noriko K Takahashi, Toshihiko Sawano, Ryu-ichi Inoue, Chikara Kaito, Kazuhisa Sekimizu, Hideki Hirakawa, Satoru Kuhara, Susumu Goto, Junko Yabuzaki, Minoru Kanehisa, Atsushi Yamashita, Kenshiro Oshima, Keiko Furuya, Chie Yoshino, Tadayoshi Shiba, Masahira Hattori, Naotake Ogasawara, Hideo Hayashi, Keiichi Hiramatsu. 2001. Whole genome sequencing of meticillin-resistant Staphylococcus aureus. Lancet. 357:1225-1240. https://doi.org/10.1016/S01406736(00)04403-2

MANJARREZ LAM, Díaz ZS, Salazar GF, Valladares CB, Gutiérrez CADC, Barbabosa PA, Talavera RM, Alonso FMU, Velázquez OV. 2012. Identificación de biotipos de Staphyloccocus aureus en vacas lecheras de producción familiar con mastitis subclínica en la región centro-este del Estado de México. Rev Mex Cienc Pecu. 3:265-274. http://www.scielo.org.mx/scielo.php?script=sci_arttext\&pid=S2007-11242012000200008

MARQUÉS VF, De Souza MMS, Mendonça ECL, Alencar TA, Pribul BR, Coelho SMO, Lasagno M, Reinoso EB. 2013. Análise fenotípica e genotípica da virulência de Staphylococcus spp. e de sua dispersão clonal como contribuição ao estudo da mastite bovina. Pesq. Vet. Bras. 33:161-170. http://www.scielo.br/scielo.php?pid=S0100736X2013000200005\&script=sci_arttext

MENZIES, R. E. 1977. Comparison of coagulase, deoxyribonuclease (DNase), and heatstable nuclease tests for identification of Staphylococcus aureus. Journal of clinical pathology, 30(7), 606-608. https://jcp.bmj.com/content/30/7/606.abstract

SATO T, Usui M, Konishi N, Kai A, Matsui H, Hanaki H, Tamura Y. 2017. Closely related methicillin-resistant Staphylococcus aureus isolates from retail meat, cows with mastitis, and humans in Japan. PloS one.12: e0187319. https://journals. plos.org/plosone/article?id=10.1371/journal.pone. 0187319 
SCHUKKEN YH, Günther J, Fitzpatrick J, Fontaine CM, Goetze L, Holst O, Leigh J, Petzl W, Schuberth JH, Sipka A, Smith EDG, Quesnell R, Watts J, Yancey R, Zerbe H, Gurjar A, Zadoks RN, Seyfert HM. 2011. Host-response patterns of intramammary infections in dairy cows. Vet Immunol Immunop. 144: 270-289. https://doi.org/10.1016/j.vetimm.2011.08.022

SCHALM OW, Noorlander DO. 1957. Experiments and observations leading to development of the California Mastitis Test. JAVMA. 130:199-204.

SHARMA-KUINKEL BK, Rude TH, Fowler VG. 2016. Pulse-field gel electrophoresis. En Bose JL. The Genetic Manipulation of Staphylococci: Methods and Protocols. Pp. 117130. https://link.springer.com/book/10.1007/978-1-4939-3158-3

SPERBER, W. Z., y Tatini, S. R. 1975. Interpretation of the tube coagulase test for identification of Staphylococcus aureus. Appl Microbiol. 29: 502-505. https://aem.asm.org/content/29/4/502.short

STRUELENS MJ, Hawkey PM, French GL, Witte W, Tacconelli E. 2009. Laboratory tools and strategies for methicillin-resistant Staphylococcus aureus screening, surveillance and typing: state of the art and unmet needs. Clin Microbiol infect. 15: 112-119. https://doi.org/10.1111/j.1469-0691.2009.02698.x

VAN SFJ, Santman-Berends IM, Lam TJ, Hogeveen H. 2016. Failure and preventive costs of mastitis on Dutch dairy farms. $J$ Dairy Sci.99:8365-8374. https://doi.org/10.3168/jds.2015-10561

VASCONCELOS NG, Ribeiro de Souza da Cunha MI. 2010. Staphylococcal enterotoxins: Molecular aspects and detection methods. Journal of Public Health and Epidemiology. 2(3):29-42. ISSN 2141-2316. http://www.academicjournals.org/jphe

WOLTER W, Castañeda H, Kloppert B, Zschock M. 2004. Mastitis Bovina. Ed., Editorial Universitaria. Pp. 18-48. ISBN. 3-7862-0099-8.

YERA PG, Ramírez W. 2016. La Prevalencia de mastitis clínica en vacas mestizas Holstein x Cebú. REDVET. 17:1-7. http://www.redalyc.org/articulo.oa?id=63646040004 http://www.veterinaria.org/revistas/redvet/n030316.html

ZSCHÖCK M, Sommerhaeuser J, Castaneda VH. 2000. Relatedness of Staphylococcus aureus isolates from bovine mammary gland suffering from mastitis in a single herd. $J$ Dairy Res. 67: 429-435. https://doi.org/10.1017/S0022029900004325 